\title{
Determinants of Consumer Impulsive Purchasing Behaviour in Medium-Large Shopping Malls in Ghana
}

\author{
Amos Arthur ${ }^{1 *}$, Isaac Owusu², Ernest Denkyi Boateng² \\ ${ }^{1}$ Faculty of Humanities and Social Science, University of Liverpool, Liverpool, UK \\ ${ }^{2}$ School of Business, Nanjing University of Information Science \& Technology, Nanjing, China \\ Email: *amonsart2007@gmail.com
}

How to cite this paper: Arthur, A., Owusu, I. and Boateng, E.D. (2020) Determinants of Consumer Impulsive Purchasing Behaviour in Medium-Large Shopping Malls in Ghana. Open Journal of Business and Management, 8, 379-395.

https://doi.org/10.4236/ojbm.2020.82024

Received: December 16, 2019

Accepted: January 13, 2020

Published: January 16, 2020

Copyright $\odot 2020$ by author(s) and Scientific Research Publishing Inc. This work is licensed under the Creative Commons Attribution International License (CC BY 4.0).

http://creativecommons.org/licenses/by/4.0/

\begin{abstract}
This research examines the determinants of consumer impulsive purchasing behaviour of Ghanaian shoppers. Churchill's and Peter's [1] conceptual model was adapted and modified as the study proposed model to verify empirical data. A sample size of 129 out of 180 was obtained from Ghanaian shoppers at medium shopping malls located in Accra and Kumasi cities in February, 2019 using a survey method. Data analysis was performed using AMOS in Statistical Packages for Social Sciences' (SPSS) software. Correlational and multiple regression analysis was used to determine the relationship and the impact between consumer's impulsive purchasing behaviour and five factors influencing consumer urge to purchase. The results showed a significant impact of the impulsive purchasing behaviour among three out of five variables used. The results findings support the assertion that store atmosphere, sales persons and sales promotion influence consumer impulsive purchasing behavior. The findings have significant marketing implication and highlight the need for business owners, financial institutions and marketers to exploit and improve marketing strategies in creating brand trust that the product and services offer.
\end{abstract}

\section{Keywords}

Impulsive Purchasing Behaviour, Sales Persons, Store Atmosphere, Sales Promotions, Shoprite Mall, Survey Methods, Ghana, Accra, Kumasi

\section{Introduction}

Recent studies indicate that every consumer, at least in a point their life-time had made an impulse purchase [2] [3]. As a result, impulsive buying behaviour 
research has gained significant attention for the past three (3) decades in many buyer-oriented economies [3] [4] [5] [6] [7]. Previous studies had largely attributed impulsive purchasing to business owners' interest in profit making by manipulating the shopping environments. However, recent literature [2] [3] [7] [8] have suggested in theory that several factors and conditions impact consumer decision to purchase impulsively.

\section{Literature Review}

\subsection{Concept and Definitions of Impulsive Purchasing}

Research of impulsive purchasing has a long history [9] and many literature views impulsive purchasing as an unplanned decision to purchase an item (or use a service) without any prior shopping plans [8] [10] [11]. The concept and how impulsive purchasing is defined as changed greatly over time and recently has been acknowledged as a complex phenomenon [2] [12] [13]. Generally, the concept means differently in theory for psychologist, consumer behaviour scientists and economics [2] [12] [13].

Although, the concept has gained more popularity in psychology and consumer behaviour studies there is considerably lack of consensus regarding the definition of impulsive purchasing behaviour [12] [13]. Rook [14] views impulsive purchasing to have occurred after a consumer makes a sudden purchase. Akram et al. [2] and Nanda [5] agreed with Rock [14] definition of "an unplanned purchasing decision(s) made prior to getting the product". However, Akram et al. [2] and Nanda [5] definition emphasized on "urge to purchase" rather than a product (see [2] [3] [14] for more information). This study adopts the definitions of impulsive purchasing advanced by both Rock [14], Akram et al. [2] and Nanda [4].

\subsection{Types of Impulsive Purchasing}

Stern [15] categorised impulsive purchasing into four distinct types; namely the pure impulsive purchasing (i.e. a consumer disrupt a usual trend of shopping); reminder impulsive purchasing (i.e. a consumer is reminded of a purchasing need upon seeing the product on display), suggestion impulsive purchasing (occurring when a consumer after seeing a product, visualises it and makes a purchase later) and planned impulsive purchasing (i.e. when a consumer is prompted by a sales promotions or adverts and partially plans in advance).

\subsection{Definitions of Consumer Behaviour}

Different researchers have provided several definition of consumer purchasing for over the years. However, we focus on consumer behaviour defined by Solomon et al. [16] as "the processes involved when individuals or groups select, use or dispose of products, services, ideas or experiences for the sole purposes of satisfying the needs and desires". According to Badgaiyan et al. [8], the psychology of impulsive purchasing can be largely explained by consumer behaviour mod- 
els. This study explored many models and adapted Churchill and Peter [1] model of the consumer purchasing process of products and services. This is model is an important aspect of marketing and helps marketers to understand how and why consumers make their purchasing decisions.

Churchill and Peter [1] decision model is summarized into five steps as illustrated in Figure 1. The five established steps (as depicted in Figure 1) in the decision-making processes are namely; need recognition, information gathering, evaluation of alternatives, the purchase decision and the post purchase behaviour. The first stage of decision-making process involves need recognition. The need recognition can be classified by either internal stimulus (i.e. a basic need such as hunger) or external stimuli (i.e. advertisement). This stage occurs in most cases naturally or set by the marketer in which case the consumer recognises a change between the present and preferred state. Also, the "need recognition" may be classified into function need, social need and merely need for change (usually occurs when a consumer income level changes from say lower/middle income class to an upper income group or vice versa) [17].

At the second stage, the consumer gets information from multiple sources by engaging with reference group, reading product information from leaflets or on the internet and/or handling of the product itself. The time used in the search varies and mainly depends on the consumer drive to obtain information. Today consumers can obtain large volume of information from different commercial sources such as advertisement etc. about products brands. After information is collected, the consumer evaluates the various alternatives available and the evaluation process varies from consumer to consumer. Some consumers may take

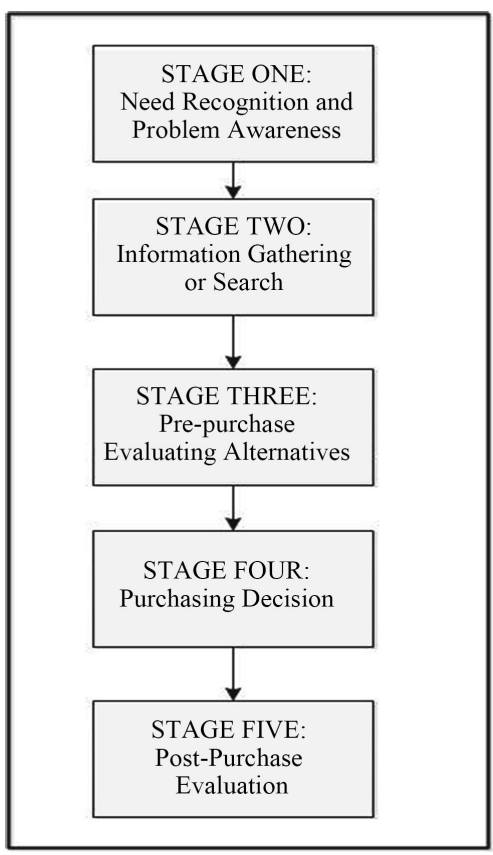

Figure 1. A systematic decision-making process (adapted and modified from Churchill's and Peter's [1]). 
little time or make no evaluation prior to making purchasing decision and this condition is termed impulse and intuition. Note that some shoppers engage in an extended problem solving process to prudently assess between the different brands available and considers substitutes during the selection process.

At the fourth stage, the shopper's purchase decision is to purchase the most desired brand. For instance, to simplify purchasing decisions, the consumer may engage in "mental shortcuts" that may lead to rushed decisions especially when limited problem solving happens prior to making a choice. Examples of such mental shortcuts include and not limited to "higher price products mean higher quality" or "purchase the same brand as previous" to specific "purchase the same brand that my friend/relative purchased" which in many cases may be unfavourable to the consumer.

The last stage is post purchase behaviour. This is stage is occurring when the shopper had bought the product and then appraise his/her level of satisfaction. A feeling of disappointment suggests that expectations towards the product are not met. On the other hand, when the product meets expectations, the consumer feels satisfied and likely to make similar purchases in future.

\subsection{Determinants of Impulsive Purchasing Behaviour}

The extent to which external factors impact on consumers purchasing behaviour to drives sales has been explored differently by different business rivals [17] [18] [19]. This suggests that more knowledge on how the various external factors when applied may assist business to utilise their resources in a more efficient and effective manner. There are numerous external factors explored in literature [20]-[27], however, this study focuses on in-store browsing, store layout, sales personnel, store-atmosphere, promotional events and reference groups.

In-store Browsing: In-store browsing is a component of impulsive purchasing process refers to consumers scanning items in shops for the purpose of obtaining information about products/services without any plan to buy or for the sake of curiosity. Researchers believe that it is in-store browsing that consumers are exposed to stimuli which creates the urge to purchase on impulse particularly when consumers spend more time browsing [20] [21] [22] believed that consumers who perform in-store browsing make unplanned buying because it is at this stage a consumer encounters desired products. Cho et al. [20] analysed the driving factors behind impulsive purchasing behaviour of consumers in Vietnam supermarkets and found that in-store browsing plays a vital role in setting off impulsive purchasing activity. Salman et al. [21] studied impulsive purchasing behaviour of sports enthusiast and their empirical results strongly support the claim that in-store browsing increases the urge for consumers to make impulse purchases.

In-store atmosphere: In-store atmosphere consists of different sensory elements such as the low or high luxury colours, noise level, light, layout, kind of music played, store scents, temperature in the store, and odour. Hussain \& Ali 
[23] found that the scent in the store significantly influences a consumer urge to purchase from the store. In a similar study, Nishanov \& Ahunjonov [24] established that a pleasant store aroma keeps consumers to stay longer in the shop which intend increases impulse purchases.

Spence et al. [25] showed that appropriate interior colours selection for a shop is the most predominant visual stimulus in store design that keeps consumers longer in the store. The longer a consumer stays around the higher the chance of engaging in impulse purchasing. This is consistent with Cho and Lee [26] study that pointed out that in-store atmosphere such as choice interior colours affects the impulse stimuli of consumers which increases impulsive purchasing behaviour in the USA. In Muruganantham and Bhakat [27] in-store atmosphere can significantly influence Iranian consumers to purchase impulsively. Similarly, Patil and Agadi [28], found that store atmosphere affect impulse purchasing behaviour. Graa et al. [29] show that in-store atmosphere such as odours plays significant role in increasing consumers to purchase impulsively. Mittal et al. [30] found that store atmosphere brings a positive feeling that creates an urge to make impulse purchase. The study hypothesis maybe formulated as follows:

In-store layout: A good store layout is designed in manner that creates convenience for consumers to view or scan through products in a given floor space. Thus a store layout refers to a well-organised sections and aisles where products arranged in such a way that improves shopping process and increases the prospects of impulsive purchasing [31]. Studies by both Pradhan [32] and Cho et al. [20] studies that found that store layout are among the factors that triggers impulse purchasing behaviour in consumers who patronise supermarkets in India and Vietnam respectively. This is consistent with findings of Muruganantham and Bhakat [27] that in-store layout is an important external factor that impacts impulsive purchasing behaviour in Iranian consumers.

Salespersons: Sales personnel are people whose work is to aid or sell items to customers who come into the store. When these sales personnel are trained well then they become an asset to the enterprise because they usually guide and help consumers in the process of purchasing. However, when sales personnel techniques create a negative picture then it impacts impulsive purchasing behaviour [33]. The sales personnel contact with the consumer is essential. The form of help offered to a consumer within the shop influence the customer willingness to purchase. Bessouh and Belkhir [34] examined the purchasing behaviour of Algerian shoppers and reported sale personnel shaped consumers' willingness to make impulse purchase.

Mihic and Kursan [35] in assessing the relationship between impulsive purchasing factors and impulsive purchasing behaviour in different customer segments found that sales personnel mostly motivate consumers to make impulse purchasing. A review paper, Muruganantham and Bhakat [27] provided an in depth description on the topic of the view of different scholars over the last six 
decades and found that sales personnel are considered an important external factor that triggers consumers' willingness to make impulse purchase.

Promotional activities: Sales promotion refers to a technique employed to induce shoppers into buying products or services [36]. This is usually done through products/services discounts and is found to have a direct effect on consumers' behaviour to make impulse purchasing [37]. Muruganantham and Bhakat [27] found promotions as a positive external factor that stimulate impulsive purchasing behaviour among consumers. Mihic and Kursan [35] studied the relationship between factors of impulsive purchasing and impulsive purchasing behaviour and concluded that in-store promotional activities trigger consumers' willingness to purchase items. Azim [36] found that promotional activities attract consumers to purchasing impulsive. Saraswat et al. [38] explained how promotional sales motivate consumers to engage in impulse purchasing among middle income earners.

Reference groups: A reference group refers to a different segment of group of people, for example relatives, friends, peers or religious groups with similar values. For example, in Pakistan, Bashir et al. [39] believed that reference groups have an important effect on impulsive purchasing behaviour. In Muruganantham and Bhakat [27] reference groups were included to the list of external factors that impact on impulsive purchasing behaviour.

Store environment: The store environment design gives consumers good feeling which is assumed to induce willingness to purchase when consumers stay much longer in the store [30]. Mittal [30] found that store environment brings a positive feeling that creates an urge to make impulse purchase. Bessouh and Belkhir [34] found that store environment increases the impulsive purchasing behaviour of Algerian youth consumers. Azim [36] reported store environment positively affect impulsive purchasing behaviour particularly consumers have an over-stimulating at the presence of a good dynamic store environment. Bessouh and Belkhir [34] found that store environmental stimuli positively impact on Algerian youth to make impulsive purchases.

\section{Research Methodology}

\section{Conceptual Model and Hypotheses Development}

In this study we adapted and modified Churchill's and Peter's [1] model to suit the objective of the research. Since impulsive purchasing is an unplanned purchasing decision(s) made prior to getting the product [2] [3] [4] [5], this study modified Churchill's and Peter's [1] model by overlooking the steps of need recognition, information search and alternative evaluation. The dependent variable used here is consumer impulsive purchasing behaviour and we selected five external factors (in-store browsing, In-store atmosphere, In-store layout, salesperson, promotional activities, store environment and reference groups). Our study developed five hypotheses to examine the relationships between consumers' impulsive purchasing behavior and the selected five external factors (see $\mathrm{Ta}$ - 
ble 1).

Research Approach: Two kinds of research approaches (i.e. qualitative and quantitative) have been proposed in literature for collecting and analysing data [40] [41]. The primary differences between the two approaches are based on philosophical and methodological reasons (see [40] for details information). This research adopts quantitative method (grounded on positivist paradigm) as the research design to collect information relative to consumer impulse buying behaviour in big Shopping malls/plaza. This approach is scientific in nature and allows the use of scientific method to collect data as well as statistical data as a tool to save time and resources [41].

Sample: The sample group was drawn from population who shop at two big malls in Ghana's two biggest cities i.e. Accra and Kumasi (Figure 2). The consumers who shop in the two shopping malls in Accra and Kumasi metropolis (referred as the respondents) constitute the sampling frame. The reason for choosing these shopping malls is as a result of the fact that they receive the largest customers (i.e. population) daily in Accra and Kumasi. According to informants report at both malls respectively, Accra and Kumasi receive nearly 800 and 500 customers every day. We used non-probability convenience sampling technique to collect information from the respondents. Convenience sampling is cost effective and provides a better speed of data collection [41].

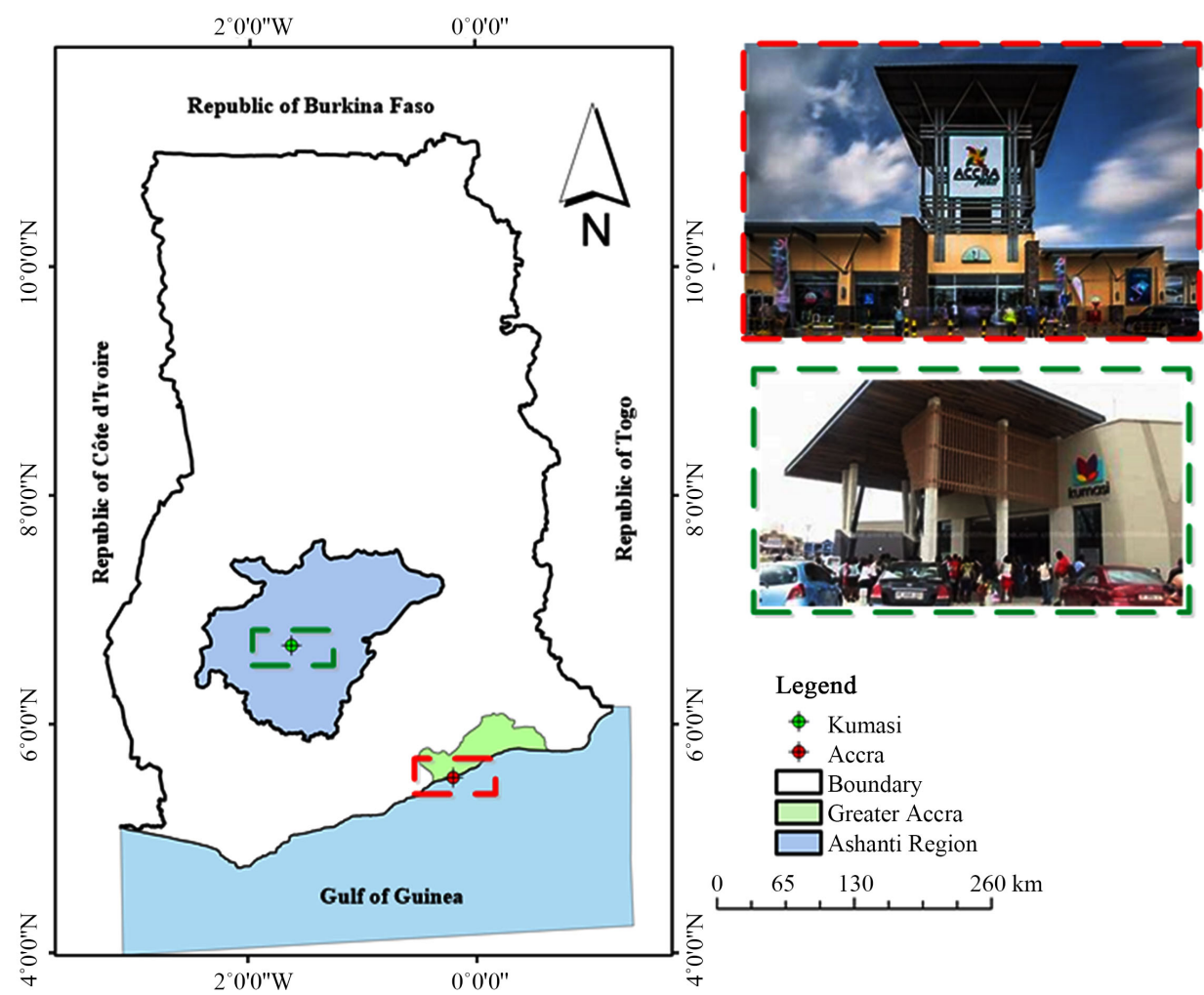

Figure 2. Boundary map of Ghana showing the Ashanti and Greater Accra regions and location of Accra and Kumasi metropolis. Red and the Green dashes around the pictures indicate Accra and Kumasi Mall respectively. Picture source is from the internet. 
Table 1. Factors influence on impulsive purchasing behaviour of Ghanaian shoppers.

\begin{tabular}{ll} 
No $\quad$ Hypothesis \\
\hline 1 & $\begin{array}{l}\text { In-browsing have a significant influence on impulsive purchasing behaviour of } \\
\text { Ghanaian shoppers }\end{array}$ \\
2 & $\begin{array}{l}\text { Sales personnel have a significant influence on impulsive purchasing behaviour of } \\
\text { Ghanaian shoppers }\end{array}$ \\
3 & $\begin{array}{l}\text { Store atmosphere have a significant influence on impulsive purchasing behaviour of } \\
\text { Ghanaian shoppers }\end{array}$ \\
& $\begin{array}{l}\text { Promotional activities have a significant influence on impulsive purchasing behaviour of } \\
\text { Ghanaian shoppers }\end{array}$ \\
& $\begin{array}{l}\text { Reference groups have a significant influence on impulsive purchasing behaviour of } \\
\text { Ghanaian shoppers }\end{array}$
\end{tabular}

Survey instrument design: We adopted an online questionnaire instrument as the survey method. The questionnaire layout was designed into five main sections. In total, 15 questions were adopted from previous studies to measure respondents' impulsive purchasing behaviour and the factors that impact their decisions. The first section (1-5) contains respondents' socio-demographic information such as age, gender, marital status, occupation and education. Section 6-7 deal with impulsive purchasing behaviour. Section 8-10 measured influence of store atmosphere, Section 11-12-measured in-store browsing, Section 13-14 measured sales person, Section 15-17 measures promotional activities and last but not least measured reference groups in Section 19-20. A 5-point Likert rating measurement scale, ranging from strongly disagree (1) to strongly agree (5) was used to measure each item. The designed questionnaire was first to my supervisor for revision and modifications after which it was pretested using 30 respondents in Accra Shoprite close to the Kotoka International Airports. The reason for piloting sample of the questionnaire is to produce data that is valid, reliable and unbiased. Afterwards, some items on the questionnaire were adjusted or re-formulated based on the feedback from the pre-testing. The final version was distributed to respondents who visited the two shopping centres in February, 2019. Within a week of administration, 129 out of 180 online questionnaires were filled and returned without any missing fields.

Reliability and Validity: We used Cronbach's coefficient alpha to assess the reliability of the scale [42]. A value of $<0.6$ indicates a weak and a value $>0.6$ indicates a strong internal consistency reliability respectively. The Cronbach alpha coefficient of all variables was greater than 0.6 is acceptable. Also, we applied confirmatory factor analysis (CFA) to examine construct validity. The CFA was performed first using Kaiser-Meyer-Olkin (KMO) and Bartletts test of sphericity tests. The KMO test and Bartletts test of sphericity tests are interpreted based on a threshold value (a value $>0.6$ ) and sig value of 0.00 is acceptable and indicative of an adequate sample size [43].

Data Analysis Methods: Statistical Packages for Social Science's (SPSS) software and AMOS was used to data analysis. Descriptive statistics presented in the 
form of frequency (or percentages), mean and standard deviation summarised the data collected using on-line survey questionnaire. In addition, correlation analysis and regression analysis were employed to assess the link among factors under consideration. The study computed Pearson correlation coefficients to determine the relationship between determinants of impulsive purchasing behaviour of Ghanaian shoppers and the results were reported based on the study hypotheses. To test the hypotheses of the study, the study performed regression analysis to determine the impact of the factors that affect impulsive purchasing behaviour of Ghanaian shoppers. Here, the researcher selects bivariate regression analysis that is compared against a significance level (0.05).

\section{Presentation and Analysis Results}

\subsection{Diagnostics Statistics}

The data was collected from 129 sampled participants using who shop at three shopping places in Accra and Kumasi using online survey. The study conducted a test of validity and reliability on the collected questionnaire and the following sub-sections presents results of the test. The Kaiser-Meyer-Olkin (KMO) showed that the sampling used in the study is adequate (a value $>0.673$ ) and the Bartletts test of sphericity tests showed the sample data is adequate for principle component analysis (sig value of 0.00) (see Table 2). The findings are consistent with previous studies. The next stage is to test for reliability and validity of the questionnaire as a research instrument. The results of reliability test for each research variable are shown in Table 3. From the table, all the research variable reported a Cronbach Alpha $\geq 0.60$ and thus acceptable. The overall Cronbach's Alpha was 0.63 .

The results in Table 4 showed the validity test of the items (indicator) to its total value using Pearson Correlation Product Moment technique formula with IBM SPSS version 22.0 software. To make a decision, the study compared the significant (2-tailed) p-value of each item (statement) variable and if the p-value $>0.01$ then the statement item is considered invalid and valid if the $\mathrm{p}$-value $<0.01$ then the statement item. The minimum correlation coefficient the study used is 0.30 and any value lower than this value is deemed unsatisfactory. Following recommendation of Kumar [40], the study removed statements items that were below 0.30 and statistically insignificant ( $p$-value $>0.01)$. Items that below the threshold were dropped and only items that met the requirement were considered valid statement items.

Table 2. KMO and Barlett's test.

\begin{tabular}{cc}
\hline Kaiser-Meyer-Olkin Measure of Sampling Adequacy & 0.673 \\
\hline Bartlett's Test of Sphericity Approx. Chi-Square & 1023.603 \\
df & 351 \\
Sig. & 0.000 \\
\hline
\end{tabular}


Table 3. The test for reliability of research instrument.

\begin{tabular}{cccc}
\hline No & Variable & Total item & Corrected Item-total Correlation \\
\hline 1 & Store Atmosphere & 2 & 0.65 \\
2 & In-store Browsing & 2 & 0.65 \\
3 & Salespersons & 2 & 0.66 \\
4 & Promotion & 3 & 0.68 \\
5 & Reference Groups & 2 & 0.67 \\
6 & Impulse Purchasing Behaviour & 7 & 0.66 \\
\hline
\end{tabular}

Table 4. The test of validity.

\begin{tabular}{|c|c|c|c|c|c|}
\hline No & Variable & $\begin{array}{l}\text { Corrected Item-total } \\
\text { Correlation }\end{array}$ & Item-total & $\begin{array}{c}\text { Decision criteria } \\
{[0.00<0.01]}\end{array}$ & Decision \\
\hline \multirow{5}{*}{1} & External factors & & & & \\
\hline & Store & & & & \\
\hline & Atmosphere & & & & \\
\hline & Sa1 & $0.748^{* *}$ & & $0.00<0.01$ & Valid \\
\hline & $\mathrm{Sa} 2$ & $0.796^{\star *}$ & & $0.00<0.01$ & Valid \\
\hline \multirow{4}{*}{2} & In-store & & & & \\
\hline & Browsing & & & & \\
\hline & $\mathrm{Sb} 1$ & $0.896^{\star *}$ & & $0.00<0.01$ & Valid \\
\hline & $\mathrm{Sb} 2$ & $0.741^{* *}$ & & $0.00<0.01$ & Valid \\
\hline \multirow[t]{3}{*}{3} & Salespersons & & & & \\
\hline & Sp1 & $0.858^{\star *}$ & & $0.00<0.01$ & Valid \\
\hline & $\mathrm{Sp} 2$ & $0.903^{* *}$ & & $0.00<0.01$ & Valid \\
\hline \multirow[t]{4}{*}{4} & Promotion & & & & \\
\hline & Pp1 & $0.744^{* *}$ & & $0.00<0.01$ & Valid \\
\hline & $\mathrm{Pp} 2$ & $0.745^{\star *}$ & & $0.00<0.01$ & Valid \\
\hline & Pp3 & $0.876^{* *}$ & & $0.00<0.01$ & Valid \\
\hline \multirow[t]{3}{*}{5} & $\begin{array}{c}\text { Reference } \\
\text { Groups }\end{array}$ & & & & \\
\hline & Rg1 & & & $0.00<0.01$ & Valid \\
\hline & Rg2 & $0.921^{* *}$ & & $0.00<0.01$ & Valid \\
\hline \multirow[t]{8}{*}{6} & $\begin{array}{c}\text { Impulse Buying } \\
\text { Behavior }\end{array}$ & & & & \\
\hline & Ipbc1 & $0.351^{* *}$ & & $0.00<0.01$ & Valid \\
\hline & Ipbc2 & $0.380^{\star *}$ & & $0.00<0.01$ & Valid \\
\hline & Ipbc3 & $0.552^{\star *}$ & & $0.00<0.01$ & Valid \\
\hline & Ipbc4 & $0.300^{* *}$ & & $0.00<0.01$ & Valid \\
\hline & Ipbc5 & $0.365^{\star *}$ & & $0.00<0.01$ & Valid \\
\hline & Ipbc6 & $0.601^{* *}$ & & $0.00<0.01$ & Valid \\
\hline & Ipbc7 & $0.453^{* *}$ & & $0.00<0.01$ & Valid \\
\hline
\end{tabular}

${ }^{*}$ Correlation is significant at the 0.01 level (2-tailed), ${ }^{*}$ Correlation is significant at the 0.05 level (2-tailed). 


\subsection{Demographic Characteristics}

The results of the respondents' demographic characteristics per the questionnaires collected are presented in Figure 3. The results for respondents' gender revealed more male than female responded to the online survey (see Figure $3(a)$ ). Respondents' age categorization also showed that the youth (i.e. "18 - 24" and " 25 - 34" years) formed the largest age groups that respondents (see Figure 3(b)). From Figure 3(c), nearly all respondents have received some form of formal education. All the participants used in this study were employed (Figure $3(d)$ ). The results captured a heterogeneity mixture of respondents' occupations ranges from banking and finance, entertainment industry, engineering professionals to health professional (Figure 3(d)). The respondents' monthly income ranged $<1000$ (US\$180) to $>4000$ (US\$ 723) [exchange 1 US $\$=5.5$ cedis] (see Figure 3(e)). Results for Marital status indicate more singles respondents than married and divorced respectively (Figure $3(\mathrm{f})$ ).

\subsection{Research Hypotheses Testing}

\subsubsection{What Factors Influence Impulsive Purchasing Behaviour of Consumers in Medium-Large Shopping Malls in Ghana?}

This part of the study analysis used Pearson's correlation coefficient to investigate the linear relationship between the variables. The study summarises the results of the five hypotheses designed for the study in Table 5.

Hypothesis 1: In-browsing have a significant influence on impulsive purchasing behaviour of Ghanaian shoppers

From the study analysis, hypothesis 1, show that impulse purchasing has no significant (at 0.05) relationship with store in-browsing at a coefficient value of -0.28 ( $\mathrm{t}$-value $=-2.99)$. Thus, the study fails to reject the alternative hypothesis that impulse purchasing has a significantly positive relationship with in-browsing.

Hypothesis 2: The role of sales personnel has a significant influence on impulsive purchasing behaviour of Ghanaian shoppers

Testing the second hypothesis showed that impulse purchasing is related with sales personnel and the result is positively significant recording a coefficient value of 0.33 ( $t$-value $=3.64$ ), thus confirming sales personnel as a factor that influences impulse purchasing.

Hypothesis 3: Store atmosphere has a significant influence on impulsive purchasing behaviour of Ghanaian shoppers

Store atmosphere was found to be statistically significant and have a positive relationship to impulse purchasing at a coefficient for this relationship with a $0.493(\mathrm{t}$-value $=2.14)$.

Hypothesis 4: The use of promotional activities has a significant influence on impulsive purchasing behaviour of Ghanaian shoppers

Promotional activities were found to be statistically significant and have a positive relationship to impulse purchasing at a coefficient for this relationship with a $0.12(\mathrm{t}$-value $=1.33)$. 

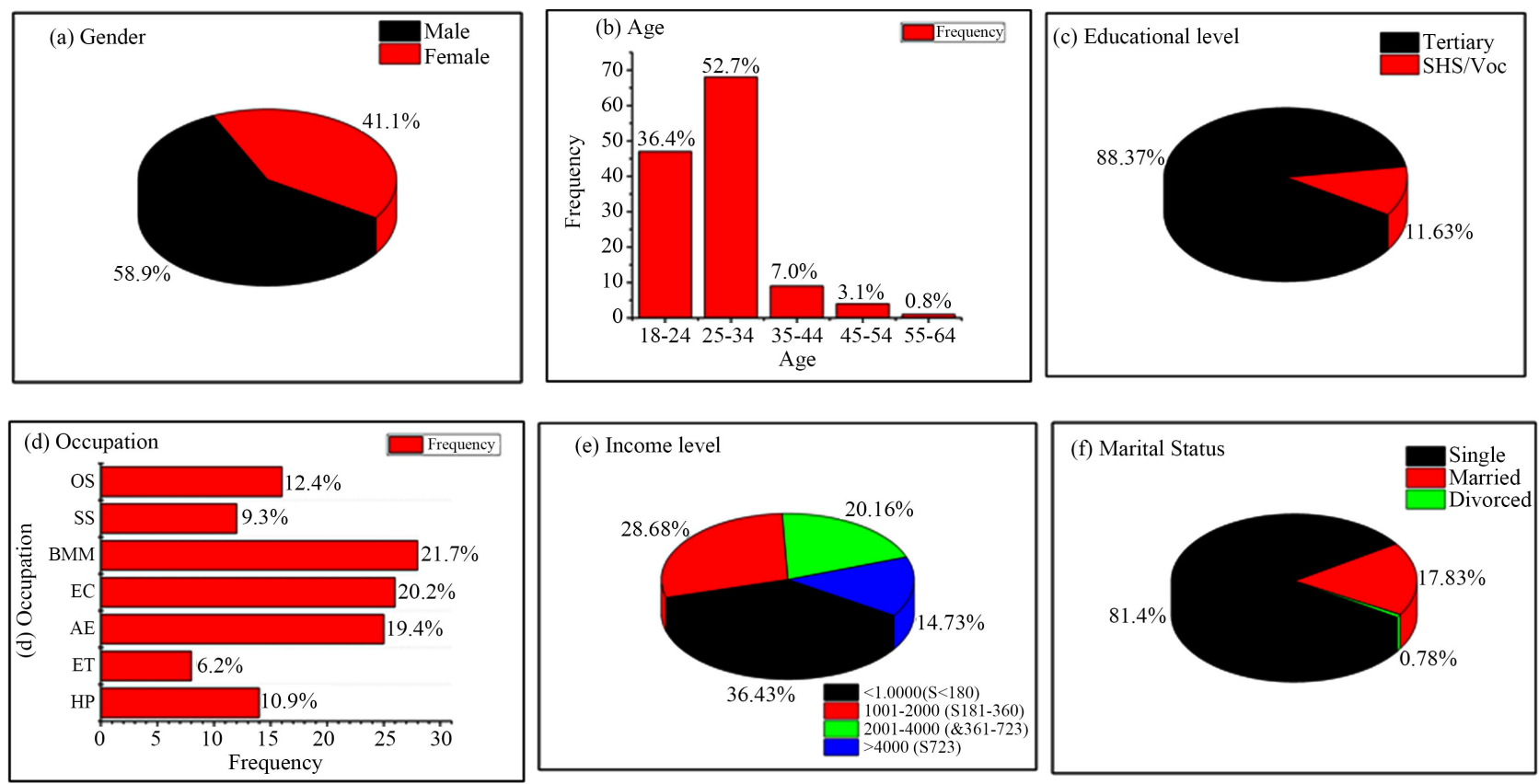

Figure 3. Demographic characteristics: (a) Gender, (b) Age, (c) Educational level, (d) Occupation, (e) Income level, (f) Marital status of respondents respectively. Note: OS = other (specify); SS = Sales related Services; BMM = Business, Marketing and Management; $\mathrm{EC}=$ Engineering and Construction; $\mathrm{AE}=$ Arts and Entertainment; $\mathrm{HP}=$ Health Profession.

Table 5. Pearson correlation analysis of dependent and independent variables.

\begin{tabular}{ccccccc}
\hline & 1 & 2 & 3 & 4 & 5 & 6 \\
\hline Impulse Purchasing (1) & 1 & & & & & \\
In-browsing (2) & $0.896^{* *}$ & 1 & & & & \\
Sales person (3) & $0.858^{\star *}$ & $0.351^{\star *}$ & 1 & & & \\
Store atmosphere (4) & $0.748^{\star *}$ & $0.380^{\star *}$ & $0.365^{* *}$ & 1 & & \\
Promotional activities (5) & $0.745^{\star *}$ & $0.552^{\star *}$ & $0.203^{* *}$ & $0.231^{\star *}$ & 1 & \\
Reference groups (6) & $0.552^{\star *}$ & $0.300^{\star *}$ & 0.031 & -0.081 & $0.196^{*}$ & 1 \\
\hline
\end{tabular}

${ }^{* *}$ Correlation is significant at the 0.01 level (2-tailed), ${ }^{*}$ Correlation is significant at the 0.05 level (2-tailed)

Hypothesis 5: The help from a reference group has a significant influence on impulsive purchasing behaviour of Ghanaian shoppers

The results presented showed that reference has not statistically significant and related to impulse purchasing and recorded a coefficient value of 0.48 $(\mathrm{t}$-value $=1.68)$.

\subsubsection{To Assess the Impact of External on Impulsive Purchasing Behaviour of Ghanaian Shoppers?}

To develop a model for this study, a stepwise multiple regression was computed in SPSS for the variables. According to literature, this method is applied to select influence of variables in the regression model by analytically adding (removing) variables that are most (least) significant during the process of iteration to finally present independent variables that provide a good fit. Table 6 summarises and presents the value of $\mathrm{R}^{2}$ for the model together with the Durbin-Watson test. 
The value of $\mathrm{R}^{2}$ and Durbin-Watson test were 0.62 and 1.708 (which according to Durbin and Watson (1951) is within the allowable limit). The table also presents the standardised and unstandardized coefficients of the variables together with their $t$ statistics (p-values). From the stepwise regression results, the study found that four of the variables significantly influence the impulse purchasing behaviour $[\mathrm{F}(4,124)=8.396, \mathrm{p} \leq 0.05]$.

\section{Discussion, Conclusion and Study Limitation}

The research supports the marketing concept that shoppers who patronize Malls or stores make impulse purchasing where sales personnel are polite and helpful to consumers, promotional activities, store layout, reference group, ambient store atmosphere, time availability and money availability influence impulsive purchasing behaviour of consumers. The study used exploratory factor analysis and regression analysis to test and develop a model of impulsive purchasing behaviour in two medium-size shopping Malls located in Accra and Kumasi in Ghana.

Our study model was derived based on the selected factors and the study findings have managerial implication on business profitability. From a managerial perspective, retailers, marketers and business owners at these malls need to focus on designing strategies and investing resource to promote impulsive purchasing activities. Thus, we have contributed new insights to understanding the determinants of online impulse purchasing activities.

The exploratory analysis reported store layout produced a lower loading factor below the threshold. Using stepwise regression, the study investigated the determinants of impulse purchasing behaviour of Ghanaian shoppers. The results from the study showed that impulsive purchasing behaviours for Ghanaian shoppers who patronize the two medium-size shopping malls are as follows: the results do support the hypothesis that sales personnel, store atmosphere and promotional activities are best determinants of impulsive purchasing behaviour.

Table 6. Regression coefficients, model summary, ANOVA test results from model estimating the determinants of impulsive purchasing.

\begin{tabular}{cccccc}
\hline Impulse purchasing & Coefficient & Standard Error & t-statistic & $\begin{array}{c}\text { P value } \\
(\mathrm{P}<0.05)\end{array}$ & $\begin{array}{c}\text { Impulse } \\
\text { purchasing (IMP) }\end{array}$ \\
\hline Coefficients & 0.053 & 0.049 & 1.08 & 0.301 & 0.053 \\
In-browsing & -0.28 & 0.184 & -2.99 & 0.205 & -0.28 \\
Sales person & 0.33 & 0.201 & 3.64 & 0.004 & 0.33 \\
Store atmosphere & 0.493 & 0.230 & 2.14 & 0.006 & 0.493 \\
Promotional activities & 0.12 & 0.161 & 1.33 & 0.001 & 0.12 \\
Reference groups & 0.46 & 0.035 & 1.68 & 0.130 & 0.46 \\
Adjusted R- squared & 0.55 & & & & 0.55
\end{tabular}

* Significance level at 95\% Source Authors construct. IMP = Impulsive purchasing; IB-In-store browsing; $\mathrm{SP}=$ store personnel; $\mathrm{SA}=$ Store Atmosphere; $\mathrm{PA}=$ promotional activities $; \mathrm{RG}=$ reference group. 
In line with previous studies, Muruganantham and Bhakat [27] found in-store atmosphere to significantly influence Iranian consumers to purchase impulsively. Patil and Agadi [28] found that store atmosphere affects impulse purchasing behaviour. Graa et al. [29] show that in-store atmosphere such as odours plays significant role in increasing consumers to purchase impulsively. Mittal [30] found that store atmosphere brings a positive feeling that creates an urge to make impulse purchase, in relation to store personnel impact on impulse purchasing.

Similarly, promotion provides strong incentives to make impulse purchasing and this study found promotion as a significant trigger to make impulse purchase in Ghana. This finding is consistent with previous work. For example, Mihic and Kursan [35] found promotional activities trigger consumers' willingness to purchase items. Azim [36] found that promotional activities attract consumers in purchasing impulsive.

On the other hand, in-store browsing and reference group do not have a direct relationship with impulse purchasing behaviour. These results are widely explored by scholars worldwide and the study results are consistent with the literature reviewed and presented in chapter two. This research has contributed to literature on the study of impulse purchasing and consumer behaviour as well as enhanced our understanding of impulse purchasing in the Ghanaian context.

The study was carried out in Ghana with largely a growing population of 30 million. The sample size used cannot be used to generalise for the entire population especially as the study was focused on only two cities. In future research, the study recommends that other cities should be included and the newly developed constructs for impulsive purchasing be developed for Ghanaian consumers.

\section{Authors' Contributions}

The first author conceptualized, design the methods, collected data, provided resources and wrote this paper. The co-authors reviewed and edited the paper.

\section{Acknowledgements}

Special gratitude to Dr. Darrell Kofkin (of University of Liverpool) for his excellent supervision of my master's thesis. The study is grateful to the anonymous respondents who participated in the online survey. Also, we are grateful to the anonymous reviewers for their insightful comments aimed at improving the paper.

\section{Conflicts of Interest}

The authors declare no conflicts of interest regarding the publication of this paper.

\section{References}

[1] Churchill, G.A. and Peter, J.P. (1998) Marketing: Creating Value for Customers. Ir- 
win/McGraw-Hill, Boston, MA.

[2] Akram, U., Hui, P., Khan, M.K., Saduzai, S.K., Akram, S. and Bhati, M.H. (2017) The Plight of Humanity: Online Impluse Shopping in China. Beijing University of Post and Telecommunications, Beijing, 73-90. https://doi.org/10.3233/HSM-171768

[3] Atulkar, S. and Kesari, B. (2017) Impulse Buying: A Consumer Trait Prospective in Context of Central India. Global Business Review, 19, 477-493. https://doi.org/10.1177/0972150917713546

[4] Das, G. (2015) Retail Shopping Behaviour: Understanding the Role of Regulatory Focus Theory. The International Review of Retail, Distribution and Consumer Research, 25, 431-445. https://doi.org/10.1080/09593969.2015.1017773

[5] Nanda, A. (2015) Analysing Multiple Dimensions of Impulse Buying. MERC Global $s$ International Journal of Management, 3, 105-115.

[6] Darrat, A.A., Darrat, M.A. and Amyx, D. (2016) How Impulse Buying Influences Compulsive Buying: The Central Role of Consumer Anxiety and Escapism. Journal of Retailing and Consumer Services, 31, 103-108. https://doi.org/10.1016/j.jretconser.2016.03.009

[7] Khuong, M.N. and Tran, T.B. (2015) Factors Affecting Impulse Buying toward Fashion Products in Ho Chi Minh City-A Mediation Analysis of Hedonic Purchase. International Journal of Trade, Economics, and Finance, 6, 223-229. https://doi.org/10.7763/IJTEF.2015.V6.473

[8] Badgaiyan, A.J. and Verma, A. (2015) Does Urge to Buy Impulsively Differ from Impulsive Buying Behaviour? Assessing the Impact of Situational Factors. Journal of Retailing and Consumer Services, 22, 145-157.

https://www.elsevier.com/locate/jretconser https://doi.org/10.1016/j.jretconser.2014.10.002

[9] Rook, H. and Hock, A. (1983) Impulse Buying. Advance in Consumer Research, 10, 562-567.

[10] Badgaiyan, A.J. and Verma, A. (2014) Intrinsic Factors Affecting Impulsive Buying Behavior; Evidence from India. Journal of Retailing and Consumer Services, 21, 537-549. https://doi.org/10.1016/j.jretconser.2014.04.003

[11] Flight, R.L., Rountree, M.M. and Beatty, S.E. (2014) Feeling the Urge: Affect in Impulsive and Compulsive Buying. Journal of Marketing Theory and Practice, 20, 453-466. https://doi.org/10.2753/MTP1069-6679200407

[12] Chang, Y. (2017) The Influence of Media Multitasking on the Impulse to Buy: A Moderated Mediation Model. Computers Human Behavior, 70, 60-66. https://doi.org/10.1016/j.chb.2016.12.071

[13] Souiden, N., Ladhari, R. and Chiadmi, N.-E. (2018) New Trends in Retailing and Services. Journal of Retailing and Consumer Services, 50, 286-288. https://doi.org/10.1016/j.jretconser.2018.07.023

[14] Rook, D.W. (1987) The Buying Impulse. Journal of Consumer Research, 14, 189-197. https://doi.org/10.1086/209105

[15] Stern, H. (1962) The Significance of Impulse Buying Today. Journal of Marketing, 26, 59-62. https://doi.org/10.1177/002224296202600212

[16] Solomon, M. (1995) Consumer Behaviour. 3rd Edition, Prentice Hall, Upper Saddle River, NJ.

[17] Acar, A.B. (2014) Do intrinsic and Extrinsic Motivation Factors Different for Generation X and Generation Y. International Journal of Business and Social Science, 5 , 12-20. 
[18] Khan, N., Hui, L.H., Chen, T.B. and Hoe, H.Y. (2016) Impulse Buying Behaviour of Generation Y in Fashion Retail. International Journal of Business and Management, 11, 144-151. https://doi.org/10.5539/ijbm.v11n1p144

[19] Bhatt, S.J. and Pandya, K. (2015) A Study on Impulse Buying Behaviour of Customer of Anand in Shopping Malls with Reference to Big Bazar and D-Mart. International Journal of Retailing and Rural Business Perspectives, 4, 1781-1787.

[20] Cho, J., Ching, G.S. and Luong, T. (2014) Impulse Buying Behaviour of Vietnamese Consumers in Supermarket Setting. International Journal of Research Studies in Management, 3, 33-50. https://doi.org/10.5861/ijrsm.2014.775

[21] Salman, M., Khan, S. and Gul, M.S.A. (2014) Factors Influencing Impulse Buying of Sports Team Merchandise in Developing Country: An Empirical Investigation. $\mathrm{Pa}$ kistan Journal of Commerce and Social Sciences, 8, 185-200.

[22] Tinne, W.S. (2010) Impulse Purchasing: A Literature Overview. ASA University Review, 4.

[23] Hussain, R. and Ali, M. (2015) Effect of Store Atmosphere on Consumer Purchase Intention. International Journal of Marketing Studies, 7, 35-43.

https://doi.org/10.5539/ijms.v7n2p35

[24] Nishanov, B. and Ahunjonov, U. (2016) The Influence of Store Characteristics on Consumers Impulse Buying Behaviour. Journal of International Business Research and Marketing, 1, 20-26. https://doi.org/10.18775/jibrm.1849-8558.2015.13.3002

[25] Spence, C., Puccinelli, N.M., Grewal, D. and Roggeveen, A.L. (2014) Store Atmospherics: A Multisensory Perspective. Psychology \& Marketing, 31, 472-488.

https://doi.org/10.1002/mar.20709

[26] Cho, J.Y. and Lee, E.-J. (2017) Impact of Interior Colors in Retail Store Atmosphere on Consumers' Perceived Store Luxury, Emotions, and Preference. Clothing and Textiles Research Journal, 35, 33-48. https://doi.org/10.1177/0887302X16675052

[27] Muruganantham, G. and Bhakat, R.S. (2013) A Review of Impulse Buying Behaviour. International Journal of Marketing Studies, 5, 149-160. https://doi.org/10.5539/ijms.v5n3p149

[28] Patil, P. and Agadi, R. (2016) Impact of Visual Merchandising on Young Customer's Apparel Impulse Buying Behaviour. International Journal of Advancement in Engineering, Technology, Management \& Applied Science, 3, 187-199.

[29] Graa, A., Dani-Elkebir, M. and Bensaid, M. (2014) The Impact of Environmental Factors on Impulse Buying Behavior Using the Mehrabian and Russell's Framework. Leonardo Journal of Sciences, 24, 101-114.

[30] Mittal, S., Sondhi, N. and Chawla, D. (2017) Process of Impulse Buying: A Qualitative Exploration. Global Business Review, 9, 1-16. https://doi.org/10.1177/0972150917713368

[31] Mohan, G., Sivakumaran, B. and Sharma, P. (2013) Impact of store environment on impulse buying behaviour. European Journal of Marketing, 47, 1711-1732. https://doi.org/10.1108/EJM-03-2011-0110

[32] Pradhan, V. (2016) Study on Impulsive Buying Behavior among Consumers in Supermarket in Kathmandu Valley. Journal of Business and Social Sciences Research, 1, 215-233. https://doi.org/10.3126/jbssr.vli2.20926

[33] Ahuja, D. (2015) Making the Pulse Impulsive: A Study of Factors Resulting Impulse Buying. International Association of Scientific Innovation and Research, 13, 50-52.

[34] Bessouh, N. and Belkhir, D.O. (2018) The Effect of Mood on Impulse Buying Behavior-Case of Algerian Buyers. Austin Journal of Business Administration and 
Management, 2, 10-23.

[35] Mihić, M. and Kursan, I. (2010) Assessing the Situational Factors and Impulsive Buying Behavior: Market Segmentation Approach. Management, 15, 47-66.

[36] Azim, A. (2013) Effect of Dynamic Environment, Customers Tendency towards Promotion and New Experiences on Impulse Buying. Management and Administrative Sciences Review, 2, 281-292.

[37] Jamal, M. and Lodhi, S. (2015) Consumer Shopping Behaviour in Relation to Factors Influencing Impulse Buying: A Case of Superstores in Karachi. Pakistan. European Journal of Business and Management, 7, 30-46.

[38] Saraswat, R., Prakash, G. and Yadav, S.K. (2012) Impact of Advertising Scheme on Impulse Buying Behavior of Consumer in: An Empirical Study of Noida City. Asia-Pacific Marketing Review, 1, 72-77.

[39] Bashir, S., Zeeshan, M. and Sabbar, S. (2013) Impact of Cultural Values and Lifestyle on Impulse Buying Behavior; A Case Study of Pakistan. International Review of Management and Business Research, 2, 193-200.

[40] Kumar, R. (2010) Research Methodology: A Step by Step Guide for Beginners. 2nd Edition, Sage Publications, London, England.

[41] Yin, R.K. (2014) Case Study Research Design and Methods. 5th Edition, Sage, Thousand Oaks, CA, $282 \mathrm{p}$.

[42] Creswell, J.W. (2003) Research Design: Qualitative, Quantitative and Mixed Methods Approaches. Sage Publications, London.

[43] Verplanken, B. and Herabadi, A. (2001) Individual Differences in Impulse Buying Tendency: Feeling and No Thinking. European Journal of Personality, 15, S71-S83.

https://doi.org/10.1002/per.423 